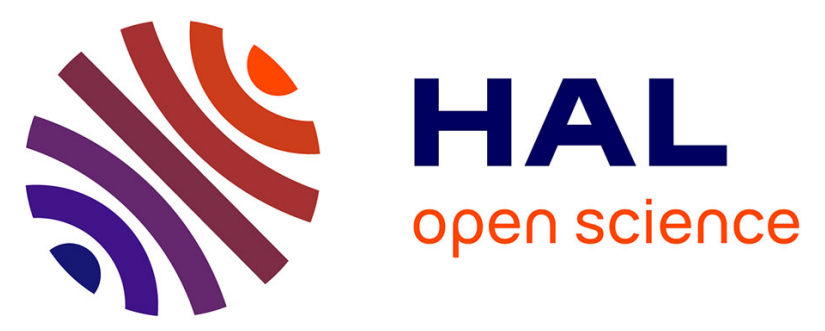

\title{
Plasma lutein and zeaxanthin and other carotenoids as modifiable risk factors for age-related maculopathy and cataract: the POLA Study.
}

Cécile Delcourt, Isabelle Carrière, Martine Delage, Pascale Barberger-Gateau, Wolfgang Schalch

\section{To cite this version:}

Cécile Delcourt, Isabelle Carrière, Martine Delage, Pascale Barberger-Gateau, Wolfgang Schalch. Plasma lutein and zeaxanthin and other carotenoids as modifiable risk factors for age-related maculopathy and cataract: the POLA Study.. Investigative Ophthalmology \& Visual Science, 2006, 47 (6), pp.2329-35. 10.1167/iovs.05-1235 . inserm-00069449

\section{HAL Id: inserm-00069449 https://www.hal.inserm.fr/inserm-00069449}

Submitted on 28 Oct 2008

HAL is a multi-disciplinary open access archive for the deposit and dissemination of scientific research documents, whether they are published or not. The documents may come from teaching and research institutions in France or abroad, or from public or private research centers.
L'archive ouverte pluridisciplinaire HAL, est destinée au dépôt et à la diffusion de documents scientifiques de niveau recherche, publiés ou non, émanant des établissements d'enseignement et de recherche français ou étrangers, des laboratoires publics ou privés. 


\section{PLASMA LUTEIN AND ZEAXANTHIN AND OTHER CAROTENOIDS AS MODIFIABLE RISK FACTORS FOR AGE-RELATED MACULOPATHY AND CATARACT: THE POLA STUDY.}

Cécile Delcourt $^{1}$, Isabelle Carrière ${ }^{2}$, Martine Delage ${ }^{3}$, Pascale Barberger-Gateau ${ }^{1}$, Wolfgang Schalch ${ }^{4}$ and the POLA Study Group 5 .

Corresponding author/reprint request : Cécile Delcourt, Inserm U593, Université Victor Segalen Bordeaux 2, 146 rue Léo Saignat, 33076 Bordeaux Cedex, France. Tel : + 393395847014 ; email : Cecile.Delcourt@isped.u-bordeaux2.fr

Word count : 4141 
1: Inserm, Research Unit U593 for Epidemiology, Public Health and Development, Bordeaux, France ; Université Victor Segalen Bordeaux 2, Bordeaux, France.

2: Inserm, E361, Montpellier, F-34093, France; Université Montpellier 1, Montpellier, F-34000 France.

3: Biochemistry Laboratory, Lapeyronie University Hospital, Montpellier, France.

4: Research and Development, DSM Nutritional Products Ltd, Kaiseraugst, Switzerland.

5 : POLA Study Group :

Coordination : Cécile DELCOURT (PhD), Annie LACROUX (MSc), Sylvie FOURREY, Marie-José COVACHO, Chantal CANET, Pierre PAILLARD, Alice PONTON-SANCHEZ (MSc), Roselyne DEFAY $(\mathrm{PhD})$, Alain COLVEZ (MD), Laure PAPOZ (PhD) (principal coordinator).

Ophthalmology : Catherine BALME-BLANCHARD (MD), Louis BALMELLE (MD), Didier CHINAUD (MD), Jacques COSTEAU (MD), Jean-Luc DIAZ (MD), Catherine DOSSA (MD), Colette GALLINARO (MD), Patrick MALAN (MD), Fabienne ROBERT (MD), Bernard ARNAUD (MD, Professor).

Biology :

Laboratoire de Biologie et Biochimie des Lipides, Montpellier : Jean-Paul CRISTOL (MD, Professor), Martine DELAGE (PhD), Marie-Hélène VERNET (PhD), Gilles FOURET, Françoise MICHEL (PhD), Claude LEGER (PhD), Bernard DESCOMPS (MD, Professor).

Laboratoire de Toxicologie Biophysique, Montpellier: Pierre MATHIEU-DAUDÉ (MD, Professor), JeanClaude MATHIEU-DAUDÉ (MD).

Institut National Agronomique, Paris : Frédéric TESSIER (PhD), Inès BIRLOUEZ-ARAGON (PhD).

Financial support :

This study was supported to the Institut National de la Santé et de la Recherche Médicale, Paris, France; by grants from the Fondation de France, Department of Epidemiology of Ageing, Paris, the Fondation pour la Recherche Médicale, Paris, the Région Languedoc-Roussillon, Montpellier, France and the Association Retina-France, Toulouse; and by financial support from Rhônes Poulenc, Essilor and Specia, and the Centre de Recherche et d'Information Nutritionnelle, Paris. 


\section{ABSTRACT}

Purpose: To assess the associations of plasma lutein and zeaxanthin, and other carotenoids, with the risk of ARM and cataract in the population-based Pathologies Oculaires Liées à l'Age (POLA) Study. Methods: Retinal photographs were graded according to the international classification. ARM was defined by the presence of late ARM (neovascular ARM, geographic atrophy) and/or soft indistinct drusen $(>125 \mu \mathrm{m})$ and/or soft distinct drusen $(>125 \mu \mathrm{m})$ associated with pigmentary abnormalities. Cataract classification was based on a standardized lens examination directly at slit lamp, according to Lens Opacities Classification System III. Plasma carotenoids were measured by HPLC, in 899 subjects of the cohort.

Results: After multivariate adjustment, the highest quintile of plasma zeaxanthin was significantly associated with reduced risk for ARM (OR $=0.07$ (95\% confidence interval $(\mathrm{Cl}): 0.01-0.58)$, p for trend $=0.005)$, nuclear cataract $(\mathrm{OR}=0.23(95 \% \mathrm{Cl}: 0.08-0.68), \mathrm{p}$ for trend $=0.003)$ and any cataract $(\mathrm{OR}=0.53(95 \% \mathrm{Cl}: 0.310 .89), \mathrm{p}$ for trend=0.01). ARM was significantly associated with combined plasma lutein and zeaxanthin (OR= $0.21(95 \% \mathrm{Cl}: 0.05-0.79), p$ for trend $=0.01$ ), and tended to be associated with plasma lutein (OR= 0.31 (95\% Cl: $0.09-1.07)$, p for trend= 0.04), while cataract showed no such associations. Among other carotenoids, only beta-carotene showed a significant negative association with nuclear cataract, but not ARM.

Conclusions: These results are strongly suggestive of a protective role of the xanthophylls, in particular zeaxanthin, for the protection against ARM and cataract. 
Although cataract and age-related maculopathy (ARM) are leading causes of blindness in the elderly ${ }^{1-}$

${ }^{3}$, their pathogenesis is not clearly understood. In recent years, there has been increasing interest in the potential role of the xanthophyll carotenoids lutein and zeaxanthin in the pathogenesis of these diseases. Lutein and zeaxanthin are selectively accumulated in the retina and are particularly dense in the macula, where they are referred to as macular pigment ${ }^{4}$. Macular pigment is thought to protect against retinal damage by filtering out phototoxic short-wavelength visible light and by defending rod outer segment membranes from oxidative stress ${ }^{5}$. In three case-control studies, subjects with high macular pigment density had a reduced risk of age-related macular degeneration ${ }^{6-8}$. Some epidemiological studies have also suggested that subjects with high dietary intakes and/or high plasma concentrations of lutein and zeaxanthin have a reduced risk of ARM ${ }^{9-12}$, although other studies did not evidence significant associations ${ }^{13-17}$. Lutein and zeaxanthin are the only carotenoids present in the lens, where they probably have a similar activity (phototoxic blue light filtering and neutralization of reactive oxygen species) ${ }^{18,}{ }^{19}$. Some epidemiological data are suggestive of a negative association of cataract with lutein and zeaxanthin status ${ }^{20-23}$, while other studies found no association ${ }^{24}$, or even a positive association ${ }^{25}$.

Epidemiological data on the association of xanthophylls with the risk of ARM and cataract remain scarce, and partly inconsistent. Moreover, until recently, lutein and zeaxanthin in plasma could not easily be separated. Most studies have therefore assessed the associations of ARM or cataract with the combined plasma concentration of lutein and zeaxanthin, thereby limiting the chances of finding specific associations of lutein or zeaxanthin with these diseases.

In the present report, we separately assessed the associations of plasma lutein and zeaxanthin as well as that of other carotenoids with the risk of ARM and cataract, in a Mediterranean populationbased study.

\section{SUBJECTS AND METHODS}

\section{Study population}

The POLA (Pathologies Oculaires Liées à l'Age) study is a prospective study, aiming at the identification of the risk factors of age-related eye diseases (cataract, age-related macular degeneration). The methods of this study have already been published elsewhere ${ }^{26}$. Briefly, inclusion criteria were: 1) being a resident of Sète (South of France); 2) being aged 60 years and over. According to the 1990 population census, there were almost 12,000 eligible residents, from which our objective was to recruit 3,000 participants. The population was informed of the study through the local 
media (television, radio and newspapers). We also contacted 4,543 residents individually by mail and telephone, using the electoral roll. Between June 1995 and July 1997, we recruited 2,584 participants.

The present study uses data from this baseline examination, which included a standardized ophthalmic examination, an interviewer-based questionnaire and fasting blood samples, collected at home on the morning of the examination. After measurements were made on plasma (lipids, glucose and antioxidants) and on red blood cells (superoxide dismutase), aliquots of plasma samples collected during the baseline examination were kept frozen at $-80^{\circ} \mathrm{C}$. In 2002-2004, plasma carotenoids were measured in these aliquots (which never have been thawed), for all participants recruited before April $1996(n=899)$.

This research followed the tenets of the Declaration of Helsinki. Participants gave written consent for the participation in the study. The design of this study has been approved by the Ethical Committee of Montpellier's University Hospital.

\section{Ophthalmic examination}

Four ophthalmologists (Louis Balmelle, MD, Jacques Costeau, MD, Jean-Luc Diaz, MD and Fabienne Robert, MD) performed the ophthalmic examinations. This examination included a record of ophthalmic history (in particular lens extraction and year of the extraction); a measure of best corrected distance visual acuity in the right and left eyes; after pupil dilation, a standardized assessment of nuclear, cortical and posterior subcapsular lens opacities at slit lamp examination according to the Lens Opacities Classification System III ${ }^{27}$ and one $50^{\circ}$ color photograph (Kodak Gold 100 ASA, Eastman Kodak Company, Rochester, NY) centered on the macular area in each eye.

\section{Photographic grading}

After film processing, retinal photographs were scanned, digitized and recorded on compact discs (Kodak procedure). The digitized images were recorded in TIFF format, with 768x512 pixels. Finally, for evaluation, photographs were examined on a $17-$ in $(43-\mathrm{cm})$ computer screen. Total magnification was approximatively $\mathrm{X} 31.5$.

For grading the photographs, we used the definitions and grids of an international classification ${ }^{28}$. We also used the standard photographs of the Winsconsin Age-Related Maculopathy Grading System ${ }^{29}$ to train the ophthalmologist and the technician in charge of the evaluation. Two levels of grading were then carried out on the fundus photographs. A preliminary grading was performed by an ophthalmologist; for subjects in whom soft drusen or pigmentary abnormalities were present anywhere 
on the photograph, a detailed grading was performed by a specially trained technician, using the international classification system ${ }^{28}$.

All lesions that were classified as geographic atrophy or neovascular macular degeneration by the ophthalmologist were discussed and adjudicated by two of the authors. In $\mathbf{4}$ cases with probable late ARM, we also asked the ophthalmologist in charge of the patient for additional information on the history of the lesion.

\section{Classification of age-related maculopathy (ARM)}

Early and late ARM were defined according to the international classification ${ }^{28}$, on the basis of $50^{\circ}$ color photographs centered on the macular area, in each eye. Late ARM was defined by the presence of neovascular ARM or geographic atrophy within the grid (3000 $\mu \mathrm{m}$ from the foveola). Neovascular ARM included serous or hemorrhagic detachment of the retinal pigment epithelium (RPE) or sensory retina, subretinal or sub-RPE hemorrhages and fibrous scar tissue. Geographic atrophy was defined as a discrete area of retinal depigmentation, $175 \mu \mathrm{m}$ in diameter or larger, characterized by a sharp border and the presence of visible choroidal vessels.

Soft distinct and indistinct drusen were larger than $125 \mu \mathrm{m}$ in diameter and with uniform density and sharp edges or decreasing density from the center outwards and fuzzy edges, respectively. Pigmentary abnormalities were defined as areas of hyperpigmentation and/or hypopigmentation (without visibility of choroidal vessels). Similar to the Blue Mountains Eye Study ${ }^{30}$ and the Rotterdam Study ${ }^{31}$, early ARM was defined by the presence in at least one eye of (a) soft indistinct drusen $(>125 \mu \mathrm{m})$ and/or (b) soft distinct drusen $(>125 \mu \mathrm{m})$ associated with pigmentary abnormalities (hyper- or hypopigmentation), in the absence of late ARM. This definition of early ARM has high predictive value for incident AMD in the POLA Study ${ }^{32}$, as in the Blue Mountains Eye Study and the Rotterdam Study.

\section{Definition of cataract}

As in the other publications from the POLA Study ${ }^{33-35}$, the presence of cataract was defined as: NC or $\mathrm{NO} \geq 4$ for nuclear opacities, $\mathrm{C} \geq 4$ for cortical opacities and $\mathrm{P} \geq 2$ for posterior subcapsular (PSC) opacities. This level of opacification corresponded to significant visual impairment in most participants. Eyes were classified as having a single type of cataract (nuclear, cortical, PSC) when only one type of opacity was present. The mixed cataract group consisted of eyes with various combinations of nuclear, cortical and PSC cataracts. Eyes which already had lens extraction formed a separate group 
(cataract surgery). All other eyes were considered as free of cataract (NO, NC and $\mathrm{C}<4, \mathrm{P}<2$ in both eyes).

\section{Interview data}

Data were collected by trained study personnel, who were unaware of ARM or cataract status. A standardized interview was performed to assess, in particular, socio-demographical variables (marital status, educational level, major lifetime occupation,...); medical history (treated hypertension, cardiovascular diseases, diabetes, knee or hip osteoarthritis,...); recording of all medications currently used; smoking and light exposure history.

The interviewer then measured height, weight, waist and hip circumferences, systolic and diastolic blood pressures.

Body mass index was defined as: weight / $\left(\right.$ height $\left.^{2}\right)$ in $\mathrm{kg} / \mathrm{m}^{2}$.

\section{Biochemical data}

Plasma samples were analyzed for lutein, zeaxanthin and 3'-dehydro-lutein as well as for other carotenoids, tocopherols, total cholesterol and triglycerides using dedicated analytical methods ${ }^{28}$. These measurements were performed at DSM Nutritional Products. None of the people involved in plasma carotenoid determination at DSM, had any access to eye diseases classifications or any other clinical finding, at any time of the study.

Previous biochemical data included measurements in plasma (cholesterol, triglycerides, vitamin $\mathrm{A}, \mathrm{E}$ and $\mathrm{C}$, glutathione peroxidase) and in red blood cells (superoxide dismutase). Measurement of plasma glutathione peroxidase concentration (plGPx) was performed by the enzyme-linked immunoassay Bioxytech pl-GPX-EIA (Bioxytech pl-Gpx-EIA, OXIS International SA, Portland, OR). Red blood cell superoxide dismutase activity (SOD) was measured by a spectrophotometric assay (Bioxytech SOD525; OXIS International SA). Lipid-standardized plasma alpha-tocopherol was defined as : alphatocopherol $(\mu \mathrm{mol}) /($ cholesterol $(\mathrm{mmol})+$ triglycerides $(\mathrm{mmol}))$.

\section{Missing data}

Among the 899 subjects with plasma carotenoid measurements, photographs gradable for ARM were available in one eye at least of 644 subjects (72\%). In the vast majority of cases (82\%), the absence of gradable photographs was due to technical failure (in particular due to problems with the flash system at the beginning of the study). Of those, 640 had complete data for all 
potential confounders and were used for the estimation of associations between ARM and plasma carotenoids.

Similarly, cataract status was available in 881 (98\%) of the 899 participants with plasma carotenoid measurements. Of those, 815 subjects had complete data for all potential confounders.

\section{Statistical analyses}

For each biochemical variable of interest, we determined the 20th and 80th percentile values, which formed three groups (low quintile, middle quintiles, high quintile). In order to take into account data from both eyes and their correlation, we used logistic Generalized Estimating Equations models for all analyses ${ }^{36}$. Age and gender-adjusted odds-ratios (and their $95 \%$ confidence interval) were first obtained with the eye disease as the dependent variable, and age, gender, and the two non-reference quintile groups of the plasma carotenoid as the independent variables ( $A$, adjusted analyses). Potential confounders were then added to the models to obtain multivariate odds-ratios ( $M$, multivariate analyses), i.e. variables which had previously been identified in the POLA Study as significant risk factors for early or late $\mathrm{ARM}^{26,37,38}$ or for each type of cataract ${ }^{33-35,39}$. For ARM, the potential confounders were therefore smoking, lipid-standardized alpha-tocopherol, plasma HDLcholesterol and BMI. For nuclear cataract, they were educational level, brown iris, smoking, plasma glutathione peroxidase $\left(\log _{10}\right)$, annual ambient solar radiation and plasma transthyretin. For cortical cataract, they were educational level, cardiovascular disease, diabetes, plasma glutathione peroxidase $\left(\log _{10}\right)$, brown iris, annual ambient solar radiation and leisure exposure to sunlight. For PSC cataract, they were educational level, oral corticosteroids, cancer, diabetes, professional exposure to sunlight and use of sunglasses. For mixed cataract, they were educational level, brown iris, diabetes, plasma glutathione peroxidase $\left(\log _{10}\right)$, professional exposure to artificial light, annual ambient solar radiation and plasma transthyretin. For cataract surgery, they were educational level, smoking, diabetes, asthma, hypertension, plasma glutathione peroxidase $\left(\log _{10}\right)$ and annual ambient solar radiation. For any cataract, they were educational level, plasma glutathione peroxidase $\left(\log _{10}\right)$, brown iris, smoking, oral corticosteroids, cancer, cardiovascular disease, hypertension, diabetes, asthma, leisure exposure to sunlight, annual ambient solar radiation, professional exposure to sunlight, professional exposure to artificial light, use of sunglasses and plasma transthyretin. 
Tests for trend were performed by entering the biochemical variable in the logistic regressions as a three category variable instead of two independent dummy variables. SAS software was used for all statistical analysis (SAS Release 9.1, SAS institute Inc., Cary, NC, USA).

\section{RESULTS}

Plasma carotenoids were highly inter-correlated (Table 1). The highest correlations were among lutein, zeaxanthin and dehydro-lutein and among alpha- and beta-carotene $(r>0.70)$. The other correlation coefficients ranged from 0.31 for alpha-carotene and lycopene to 0.62 for beta-carotene and beta-cryptoxanthin.

The associations of plasma carotenoids with the risk of ARM are presented in Table 2. Of the 640 subjects (1193 eyes) with complete data for ARM statistical analyses, 10 eyes (7 subjects) had late ARM and 45 eyes (34 subjects) had early ARM. Because of the small number of subjects with late ARM, we pooled early and late ARM in all statistical analyses. Plasma lutein and zeaxanthin showed strong inverse association with ARM. The association with plasma zeaxanthin was particularly strong. Compared with subjects having low levels of zeaxanthin $(<0.04 \mu \mathrm{mol} / \mathrm{L})$, subjects with high levels of plasma zeaxanthin $(>0.09 \mu \mathrm{mol} / \mathrm{L})$ had a $93 \%$ reduced risk for ARM. Globally, subjects with high total plasma lutein and zeaxanthin $(>0.56 \mu \mathrm{mol} / \mathrm{L})$ had a $79 \%$ reduced risk for ARM compared with subjects with low total plasma lutein and zeaxanthin $(<0.25 \mu \mathrm{mol} / \mathrm{L})$. Plasma dehydro-lutein, alpha and beta-carotene, beta-cryptoxanthin and lycopene did not show significant associations with the risk for ARM. Further adjustment for smoking, lipid-standardized alpha-tocopherol, HDL-cholesterol and BMI did not materially affect the results (Table 2).

With respect to cataract, among the 1625 eyes ( 815 subjects) with complete data for cataract statistical analyses, 86 eyes (59 subjects) had nuclear only, 47 eyes (30 subjects) cortical only, 98 eyes (53 subjects) PSC only, 93 eyes (66 subjects) mixed cataracts and 94 eyes had cataract surgery (33 subjects with bilateral cataract surgery). The remaining 1207 eyes (574 subjects) without any type of cataract served as controls for all statistical analyses.

As shown in Table 3, after adjustment for age and gender, only plasma zeaxanthin showed a strong inverse association with nuclear cataract. Compared to subjects with low plasma zeaxanthin $(<0.04$ $\mu \mathrm{mol} / \mathrm{L})$, those with high plasma zeaxanthin $(>0.08 \mu \mathrm{mol} / \mathrm{L})$ had a $75 \%$ decreased risk for nuclear cataract. The other types of cataract did not show any significant associations with plasma zeaxanthin. 
Globally, the risk for any cataract was reduced by $43 \%$ in subjects with high plasma zeaxanthin Similarly, subjects with high plasma dehydro-lutein $(>0.07 \mu \mathrm{mol} / \mathrm{L})$ had a significantly $66 \%$ reduced risk for nuclear cataract, compared to subjects with low plasma dehydro-lutein $(<0.03 \mu \mathrm{mol} / \mathrm{L})(\mathrm{p}=$ 0.05). By contrast, plasma lutein was not significantly associated with any type of cataract. Globally, total lutein and zeaxanthin showed a trend towards an inverse association with nuclear, mixed and any cataract, which did not reach statistical significance.

These associations were not materially affected by further multivariate adjustment: in particular, the associations of plasma zeaxanthin with nuclear $(\mathrm{OR}=0.23(0.08-0.68), \mathrm{p}$ for trend $=0.003)$ and any cataract $(\mathrm{OR}=0.53(0.31-0.89), \mathrm{p}$ for trend $=0.01)$ and of plasma dehydro-lutein with nuclear cataract $(\mathrm{OR}=0.32(0.10-1.02), \mathrm{p}$ for trend $=0.04)$ remained statistically significant. The association of dehydro-lutein with any cataract became significant after multivariate adjustment (OR=0.55 $(0.31-0.97), p$ for trend $=0.04)$.

As shown in Table 4, plasma beta-cryptoxanthin, alpha- and beta-carotene and lycopene did not show any significant associations with any type of cataract. However, the association of beta-carotene with nuclear cataract became statistically significant after multivariate adjustment (OR=0.38 $(0.14-1.04), p$ for trend $=0.04)$.

\section{DISCUSSION}

In the present study, high plasma zeaxanthin was associated with a markedly reduced risk for ARM and nuclear cataract. High plasma lutein and total lutein and zeaxanthin were also associated with a reduced risk for ARM, while they were not significantly associated with cataract. Although there were important correlations among carotenoids, we observed no important associations of ARM or cataract with the other studied carotenoids (alpha- and beta-carotene, beta-cryptoxathin, lycopene), in line with the fact that only lutein and zeaxanthin are present in the retina and in the lens.

With respect to ARM, our results are consistent with those of a recent cross-sectional study performed in England ${ }^{12}$. The authors reported a significant $50 \%$ reduced risk for early or late ARM (OR= $0.5(0.2$ $-1.0), p=0.05)$ in subjects with high plasma zeaxanthin $(>0.05 \mu \mathrm{mol} / \mathrm{L})$, compared to subjects with low levels $(<0.03 \mu \mathrm{mol} / \mathrm{L})$. The association with plasma lutein was weaker and did not reach statistical significance $(\mathrm{OR}=0.6(0.3-1.1), \mathrm{p}=0.12)$. In our study, the associations with plasma zeaxanthin and lutein were even stronger ( $\mathrm{OR}=0.07$ and $\mathrm{OR}=0.31$, respectively), and both were significant. This may 
be due to the higher values in the highest quintile of zeaxanthin $(>0.09 \mu \mathrm{mol} / \mathrm{L})$ and lutein $(>0.41$ $\mu \mathrm{mol} / \mathrm{L}$ ) in this Mediterranean population, probably associated with higher dietary intakes of these xanthophylls, which are mainly provided by green-leafy vegetables such as spinach or broccoli. Previous studies did not differentiate lutein from zeaxanthin. In the Eye Disease Case-Control Study, plasma lutein and zeaxanthin (LZ) $(>0.67 \mathrm{vs}<0.25 \mu \mathrm{mol} / \mathrm{L})$ was associated with a reduced risk for neovascular ARM, with estimates close to the present study $(\mathrm{OR}=0.3(0.2-0.6))^{10}$. Dietary $L Z$ were also inversely associated with neovascular AMD $(\mathrm{OR}=0.43(0.2-0.7))^{9}$. Similarly, a recent casecontrol study from the Netherlands showed a significantly reduced risk for neovascular ARM in subjects with high dietary $L Z(O R=0.41(0.20-0.91)){ }^{11}$. In the Third National Health and Nutrition Examination Survey (NHANES III), high plasma levels of LZ tended to be associated with a reduced risk for late $\operatorname{AMD}(\mathrm{OR}=0.6(0.2-1.9))$, but this association was far from significant ${ }^{13}$. Similarly, high dietary intakes of $L Z$ tended to be associated with reduced risk of late ARM $(O R=0.5(0.1-1.6))$, but this association was significant only in subjects younger than 80 years old $(O R=0.1(0.0-0.9))^{13}$. In a case-control study nested in the Beaver Dam Eye Study, the association between late ARM and plasma $L Z$ was not significant $(O R=0.7(0.4-1.4)$ for $L Z>0.17$ vs $L Z<0.17 \mu \mathrm{mol} / \mathrm{L}){ }^{14}$. In a $50 \%$ random sample of the Beaver Dam Eye Study, no significant associations were found between dietary LZ and prevalent early or late ARM ${ }^{15}$ or incident early ARM ${ }^{16}$. Similarly, there were no significant associations of dietary LZ with incident early ARM in the Blue Mountains Eye Study ${ }^{17}$.

With respect to cataract, we found an association of nuclear cataract with plasma zeaxanthin but not with plasma lutein. In a cross-sectional study performed in England ${ }^{40}$, a non significant inverse association of nuclear cataract with both zeaxanthin $(O R=0.7(0.4-1.4))$ and lutein $(O R=0.8$ (0.4-1.5)) was found. In a Spanish case-control study, no significant associations were found between dietary lutein or dietary zeaxanthin with the risk of cataract ${ }^{24}$. However, the statistical analyses did not distinguish the different types of cataract. Another case-control study performed in Spain showed an increased risk for cataract in subjects with high plasma lutein $(O R=1.8(1.1-3.1))$ or zeaxanthin $\left(\mathrm{OR}=2.2(1.3-3.7)^{25}\right.$. However, age distribution was very different between cases and controls, and potential confounding by known risk factors was not accounted for.

Previous studies gave results for pooled lutein and zeaxanthin, which may have obscured associations with cataract, in the case only zeaxanthin is associated with cataract. In our study, plasma total lutein 
and zeaxanthin were associated with an odds-ratio of 0.53 for nuclear cataract and of 0.45 for mixed cataract, and with odds-ratios close to 1 for cortical and PSC cataract. In a prospective analysis of the Beaver Dam Eye Study, high dietary intakes of lutein and zeaxanthin were associated with a reduced risk for incident nuclear cataract $(\mathrm{OR}=0.5(0.3-0.8))^{22}$, while in a subsample, the association with plasma lutein and zeaxanthin was in the same direction but did not reach statistical significance $(O R=$ $0.7(0.3-1.6))^{41}$. In the Nutrition and Vision Project, high dietary intakes of lutein and zeaxanthin were associated with a reduced risk for nuclear cataract $(\mathrm{OR}=0.52(0.29-0.91))^{23}$, while their associations with cortical and PSC cataracts were not statistically significant ${ }^{42}$. Two large prospective studies also showed a reduced risk for cataract surgery in subjects with high dietary intakes of lutein and zeaxanthin ${ }^{20,21}$.

Although plasma lutein and zeaxanthin are highly correlated, our results suggest a stronger association of plasma zeaxanthin than lutein with the risk of ARM and cataract, consistent with the study from Gale et al ${ }^{12,40}$. The hypothesis of a more important role of zeaxanthin in retina and lens health is supported by several lines of evidence. Firstly, the ratio of zeaxanthin to lutein is much higher in the central retina (1:1 in the macula, $2: 1$ in the fovea) ${ }^{19,43}$ and in the lens $(1: 1)^{19}$ than it is in the plasma (about 1:5 in the present study), suggesting that the eye preferentially accumulates zeaxanthin. Moreover, although both lutein and zeaxanthin protect liposomal membranes from light induced oxidative stress, zeaxanthin appears to be a better photoprotector during prolonged UV exposure ${ }^{44}$. This may be due to a different orientation of lutein and zeaxanthin in biological membranes ${ }^{44}$. Zeaxanthin is also particularly effective in protecting lipid membranes against oxidation by peroxyl radicals ${ }^{45}$. More data are needed on the specific associations of lutein and zeaxanthin with ARM and cataract, both at the biological and epidemiological levels.

Our study has several limitations. First, our sample under-represents the older persons and overrepresents the middle and upper social classes, by comparison with the whole eligible population ${ }^{26}$. The subjects of this study may thus be healthier and have different lifestyle habits, in particular concerning diet and physical activity, than the general population. This is likely to have affected the distribution of plasma carotenoids or the prevalence of eye diseases. However, it is unlikely to have affected the association between eye diseases and plasma measurements. Moreover, although a selection bias cannot be dismissed, the prevalence rates of cataract and ARM and their associations with their known risk factors (i.e. smoking, diabetes, corticosteroids, light exposure...) are similar to those observed in other studies ${ }^{26,34,35}$. 
Since samples were kept frozen at $-80^{\circ} \mathrm{C}$ for about 7 years, it is possible that the observed carotenoid levels were underestimated in the present study, due to long-term instability. For instance, for beta-carotene, a $20 \%$ decrease in plasma level was observed over a 7 years storage at $-80^{\circ} \mathrm{C}^{46}$. Since all samples were treated and stored in a similar manner, this is however unlikely to have affected the associations between eye diseases and plasma measurements.

The relative small numbers of subjects affected by ARM and cataract constitutes another limitation. In particular, due to the very low number of subjects with late ARM, we were unable to separate early and late ARM in statistical analyses. Our results therefore reflect mainly the associations of plasma carotenoids with early ARM. The small number of subjects in some cataract types (in particular cortical cataract) may also have generated insufficient statistical power to detect associations with plasma carotenoids. In particular, this may be one reason for the absence of association of plasma xanthophylls with mixed cataract and cataract surgery. Indeed, it is rather surprising that these two groups of cataract, which usually include a large number of nuclear opacities, were not significantly associated with zeaxanthin, while nuclear cataract was. Although their odds-ratios were not statistically significant, they were in the same direction and were not statistically different from the one for nuclear cataract. These negative relationships probably contributed to the global statistically significant negative association with "any cataract".

In addition, cataract was graded according to LOCS III, directly at slit lamp, instead of photographic grading. This may have added misclassification in cataract status, and therefore biased the observations towards the null hypothesis. Another limitation is due to the high number of comparisons made (up to 48 for cataract). We therefore cannot exclude that some of the observed associations were due to chance finding.

In observational studies, the concern is always about confounding. We have therefore performed multivariate adjustments, to take into account all known risk factors for cataract and ARM. In addition to age, gender and educational level, specific factors were used for the different types of cataract and ARM. The selected factors are those identified in previous analyses of the POLA Study for ARM ${ }^{26,37}$, ${ }^{38}$ and cataract ${ }^{33-35,39}$. The associations of plasma zeaxanthin and lutein with eye diseases were not strongly affected by these adjustments. 
Since this study is cross-sectional, we cannot assume that the low plasma zeaxanthin and lutein levels preceded the development of cataract or ARM. It is possible that participants with eye disease have modified their diet after developing visual impairment. These results must therefore be confirmed in prospective studies. Whether increasing dietary intakes of lutein and zeaxanthin, through dietary modifications or nutritional supplements, may have a preventive effect against ARM or cataract can be established only by interventional studies. A small interventional study has recently suggested that lutein supplements may improve visual function in subjects with geographic atrophy ${ }^{47}$.

In conclusion, in this Mediterranean population, high plasma zeaxanthin levels were associated with reduced risk for ARM and nuclear cataract. High plasma lutein levels were also associated with reduced risk for ARM. These data are consistent with previous epidemiological studies and suggest that lutein and zeaxanthin may be important for protecting against ARM and cataract, in particular in its nuclear localization. These data need to be confirmed by other studies, in particular prospective epidemiological and interventional studies.

\section{Acknowledgement}

We thank Dr. Volker Spitzer and his colleagues at the Analytical Department of DSM Nutritional Products in Kaiseraugst for performing the analytical work.

\section{References}

1. Asbell PA, Dualan I, Mindel J, Brocks D, Ahmad M, Epstein S. Age-related cataract. Lancet. 2005;365:599-609.

2. Klein R, Wang Q, Klein BE, Moss SE, Meuer SM. The relationship of age-related maculopathy, cataract, and glaucoma to visual acuity. Invest. Ophthalmol. Vis. Sci. 1995;36:182-191. 3. Evans JR, Fletcher AE, Wormald RP. Causes of visual impairment in people aged 75 years and older in Britain: an add-on study to the MRC Trial of Assessment and Management of Older People in the Community. Br. J. Ophthalmol. 2004;88:365-370.

4. Bone RA, Landrum JT, Tarsis SL. Preliminary identification of the human macular pigment. Vision. Res. 1985;25:1531-1535.

5. Schalch W, Dayhaw-Barker P, Barker FM. The carotenoids of the human retina. In: Taylor A, editor. Nutritional and environmental influences of the eye. Boca Raton (USA): CRC Press, 1999:215250. 
6. Beatty S, Murray IJ, Henson DB, Carden D, Koh H, Boulton ME. Macular pigment and risk for age-related macular degeneration in subjects from a Northern European population. Invest.

Ophthalmol. Vis. Sci. 2001;42:439-446.

7. Bone RA, Landrum JT, Mayne ST, Gomez CM, Tibor SE, Twaroska EE. Macular pigment in donor eyes with and without AMD: a case-control study. Invest. Ophthalmol. Vis. Sci. 2001;42:235240.

8. Bernstein PS, Zhao DY, Wintch SW, Ermakov IV, McClane RW, Gellermann W. Resonance Raman measurement of macular carotenoids in normal subjects and in age-related macular degeneration patients. Ophthalmology. 2002;109:1780-1787.

9. Seddon JM, Ajani UA, Sperduto RD, et al. Dietary carotenoids, vitamins A, C, and E, and advanced age-related macular degeneration. Eye Disease Case-Control Study Group. Jama. 1994;272:1413-1420.

10. Eye Disease Case-control Study G. Antioxidant status and neovascular age-related macular degeneration. Arch. Ophthalmol. 1993;111:104-109.

11. Snellen EL, Verbeek AL, Van Den Hoogen GW, Cruysberg JR, Hoyng CB. Neovascular agerelated macular degeneration and its relationship to antioxidant intake. Acta. Ophthalmol. Scand. 2002;80:368-371.

12. Gale CR, Hall NF, Phillips DI, Martyn CN. Lutein and zeaxanthin status and risk of age-related macular degeneration. Invest. Ophthalmol. Vis. Sci. 2003;44:2461-2465.

13. Mares Perlman JA, Fisher Al, Klein R, et al. Lutein and zeaxanthin in the diet and serum and their relation to age-related maculopathy in the third national health and nutrition examination survey. Am. J. Epidemiol. 2001;153:424-432.

14. Mares Perlman JA, Brady WE, Klein R, et al. Serum antioxidants and age-related macular degeneration in a population-based case-control study. Arch. Ophthalmol. 1995;113:1518-1523. 15. Mares Perlman JA, Klein R, Klein BE, et al. Association of zinc and antioxidant nutrients with age-related maculopathy. Arch. Ophthalmol. 1996;114:991-997.

16. Vandenlangenberg GM, Maresperlman JA, Klein R, Klein BEK, Brady WE, Palta M. Associations between antioxidant and zinc intake and the 5-year incidence of early age-related maculopathy in the Beaver Dam Eye Study. Am. J. Epidemiol. 1998;148:204-214.

17. Flood V, Smith W, Wang JJ, Manzi F, Webb K, Mitchell P. Dietary antioxidant intake and incidence of early age-related maculopathy: the Blue Mountains Eye Study. Ophthalmology. 2002;109:2272-2278. 
18. Yeum KJ, Shang FM, Schalch WM, Russell RM, Taylor A. Fat-soluble nutrient concentrations in different layers of human cataractous lens. Curr. Eye. Res. 1999;19:502-505.

19. Bernstein PS, Khachik F, Carvalho LS, Muir GJ, Zhao DY, Katz NB. Identification and quantitation of carotenoids and their metabolites in the tissues of the human eye. Exp. Eye. Res. 2001;72:215-223.

20. Chasan Taber L, Willett WC, Seddon JM, et al. A prospective study of carotenoid and vitamin A intakes and risk of cataract extraction in US women. Am. J. Clin. Nutr. 1999;70:509-516.

21. Brown L, Rimm EB, Seddon JM, et al. A prospective study of carotenoid intake and risk of cataract extraction in US men. Am. J. Clin. Nutr. 1999;70:517-524.

22. Lyle BJ, Maresperlman JA, Klein BEK, Klein R, Greger JL. Antioxidant intake and risk of incident age-related nuclear cataracts in the Beaver Dam Eye Study. Am. J. Epidemiol. 1999;149:801809.

23. Jacques PF, Chylack Lt JR, Hankinson SE, et al. Long-term nutrient intake and early agerelated nuclear lens opacities. Arch. Ophthalmol. 2001;119:1009-1019.

24. Valero MP, Fletcher AE, De Stavola BL, Vioque J, Alepuz VC. Vitamin C is associated with reduced risk of cataract in a Mediterranean population. J. Nutr. 2002;132:1299-1306.

25. Olmedilla B, Granado F, Blanco I, Herrero C, Vaquero M, Millan I. Serum status of carotenoids and tocopherols in patients with age-related cataracts: a case-control study. J. Nutr. Health. Aging. 2002;6:66-68.

26. Delcourt C, Diaz JL, Ponton-sanchez A, Papoz L, The Pola Study Group. Smoking and agerelated macular degeneration: The POLA study. Arch. Ophthalmol. 1998;116:1031-1035.

27. Chylack Lt JR, Wolfe JK, Singer DM, et al. The Lens Opacities Classification System III. The Longitudinal Study of Cataract Study Group. Arch. Ophthalmol. 1993;111:831-836.

28. Bird AC, Bressler NM, Bressler SB, et al. An international classification and grading system for age-related maculopathy and age-related macular degeneration. The International ARM Epidemiological Study Group. Surv. Ophthalmol. 1995;39:367-374.

29. Klein R, Davis MD, Magli YL, Segal P, Klein BEK, Hubbard L. The Wisconsin age-related maculopathy grading system. Ophthalmology. 1991;98:1128-1134.

30. Mitchell P, Wang JJ, Foran S, Smith W. Five-year incidence of age-related maculopathy lesions: the Blue Mountains Eye Study. Ophthalmology. 2002;109:1092-1097.

31. Van Leeuwen R, Klaver CC, Vingerling JR, Hofman A, De Jong PT. The risk and natural course of age-related maculopathy: follow-up at $61 / 2$ years in the Rotterdam study. Arch. Ophthalmol. 2003;121:519-526. 
32. Delcourt C, Lacroux A, Carriere I, Group. PS. The Three-Year Incidence of Age-Related Macular Degeneration: The "Pathologies Oculaires Liees a l'Age" (POLA) Prospective Study. Am J Ophthalmol 2005;140:924-6.

33. Delcourt C, Cristol JP, Leger CL, Descomps B, Papoz L, And The Pola Study Group. Associations of antioxidant enzymes with cataract and age-related macular degeneration. The POLA Study. Ophthalmology. 1999;106:215-222.

34. Delcourt C, Cristol JP, Tessier F, et al. Risk factors for cortical, nuclear, and posterior subcapsular cataracts: the POLA Study. Pathologies oculaires liees a l'age. Am. J. Epidemiol. 2000;151:497-504.

35. Delcourt C, Carriere I, Ponton Sanchez A, et al. Light exposure and the risk of cortical, nuclear, and posterior subcapsular cataracts: the Pathologies Oculaires Liees a l'Age (POLA) Study. Arch. Ophthalmol. 2000;118:385-392.

36. Zeger SL, Liang KY, Albert PS. Models for longitudinal data: a generalized estimating equation approach. Biometrics 1988;44:1049-1060.

37. Delcourt C, Cristol JP, Tessier F, et al. Age-related macular degeneration and antioxidant status in the POLA study. Pathologies Oculaires Liees a l'Age. Arch. Ophthalmol. 1999;117:13841390.

38. Delcourt C, Michel F, Colvez A, Lacroux A, Delage M, Vernet MH. Associations of cardiovascular disease and its risk factors with age-related macular degeneration: the POLA study. Ophthalmic. Epidemiol. 2001;8:237-249.

39. Delcourt C, Dupuy AM, Carriere I, Lacroux A, Cristol JP. Albumin and transthyretin as risk factors for cataract: the POLA study. Arch. Ophthalmol. 2005;123:225-232.

40. Gale CR, Hall NF, Phillips DI, Martyn CN. Plasma antioxidant vitamins and carotenoids and age-related cataract. Ophthalmology. 2001;108:1992-1998.

41. Lyle BJ, Maresperlman JA, Klein BEK, et al. Serum carotenoids and tocopherols and incidence of age-related nuclear cataract. Am. J. Clin. Nutr. 1999;69:272-277.

42. Taylor A, Jacques PF, Chylack Lt JR, et al. Long-term intake of vitamins and carotenoids and odds of early age-related cortical and posterior subcapsular lens opacities. Am. J. Clin. Nutr. 2002;75:540-549.

43. Bone RA, Landrum JT, Fernandez L, Tarsis SL. Analysis of the macular pigment by HPLC: retinal distribution and age study. Invest. Ophthalmol. Vis. Sci. 1988;29:843-849. 
44. Sujak A, Gabrielska J, Grudzinski W, Borc R, Mazurek P, Gruszecki WI. Lutein and zeaxanthin as protectors of lipid membranes against oxidative damage: the structural aspects. Arch. Biochem. Biophys. 1999;371:301-307.

45. Woodall AA, Britton G, Jackson MJ. Carotenoids and protection of phospholipids in solution or in liposomes against oxidation by peroxyl radicals: relationship between carotenoid structure and protective ability. Biochim Biophys Acta 1997;1336:575-86.

46. Aebischer CP, Schierle J, Schuep W. Simultaneous determination of retinol, tocopherols, carotene, lycopene, and xanthophylls in plasma by means of reversed-phase high-performance liquid chromatography. Methods. Enzymol. 1999;299:348-362.

47. Richer S, Stiles W, Statkute L, et al. Double-masked, placebo-controlled, randomized trial of lutein and antioxidant supplementation in the intervention of atrophic age-related macular degeneration: the Veterans LAST study (Lutein Antioxidant Supplementation Trial). Optometry. 2004;75:216-230. 
Table 1. Correlation coefficients among plasma carotenoids (after logarithmic transformation) in the POLA Study $(\mathbf{n}=\mathbf{8 9 9})$.

\begin{tabular}{|c|c|c|c|c|c|c|c|}
\hline & Lutein & $\begin{array}{l}\text { Zeaxan- } \\
\text { thin }\end{array}$ & $\begin{array}{l}\text { Dehydro- } \\
\text { lutein }\end{array}$ & $\begin{array}{c}\text { Beta } \\
\text { carotene }\end{array}$ & $\begin{array}{c}\text { Alpha } \\
\text { carotene }\end{array}$ & $\begin{array}{c}\text { Beta } \\
\text { cryptoxanthin }\end{array}$ & Lycopene \\
\hline Lutein & 1 & 0.74 & 0.86 & 0.54 & 0.53 & 0.45 & 0.32 \\
\hline Zeaxanthin & & 1 & 0.80 & 0.43 & 0.33 & 0.56 & 0.32 \\
\hline Dehydro-lutein & & & 1 & 0.45 & 0.43 & 0.45 & 0.33 \\
\hline Beta carotene & & & & 1 & 0.77 & 0.62 & 0.48 \\
\hline $\begin{array}{l}\text { Alpha } \\
\text { carotene }\end{array}$ & & & & & 1 & 0.43 & 0.31 \\
\hline $\begin{array}{l}\text { Beta } \\
\text { cryptoxanthin }\end{array}$ & & & & & & 1 & 0.43 \\
\hline Lycopene & & & & & & & 1 \\
\hline
\end{tabular}


Table 2. Associations of age-related maculopathy (early or late, 55 eyes) with plasma carotenoids in the POLA Study (odds-ratio (95\% confidence interval)).

\begin{tabular}{|c|c|c|c|c|c|}
\hline \multicolumn{2}{|c|}{ Plasma carotenoids $(\mu \mathrm{mol} / \mathrm{l})$} & \multicolumn{2}{|c|}{ Age- and gender-adjusted } & \multicolumn{2}{|c|}{ Multivariate adjusted ${ }^{*}$} \\
\hline \multirow[t]{4}{*}{ Lutein } & $<0.18$ & 1.0 & & 1.0 & \\
\hline & $0.18-0.41$ & 0.45 & $(0.22-0.94)$ & 0.40 & $(0.18-0.89)$ \\
\hline & $\geq 0.41$ & 0.31 & $(0.09-1.05)$ & 0.31 & $(0.09-1.07)$ \\
\hline & $P$ for trend & & 0.03 & & 0.04 \\
\hline \multirow[t]{4}{*}{ Zeaxanthin } & $<0.04$ & 1.0 & & 1.0 & \\
\hline & $0.04-0.09$ & 0.76 & $(0.37-1.57)$ & 0.74 & $(0.35-1.59)$ \\
\hline & $\geq 0.09$ & 0.07 & $(0.01-0.61)$ & 0.07 & $(0.01-0.58)$ \\
\hline & $P$ for trend & & 0.005 & & 0.005 \\
\hline \multirow[t]{4}{*}{ Dehydro-lutein } & $<0.03$ & & 1.0 & & 1.0 \\
\hline & $0.03-0.07$ & 0.51 & $(0.24-1.11)$ & 0.52 & $(0.22-1.20)$ \\
\hline & $\geq 0.07$ & 0.38 & $(0.11-1.29)$ & 0.39 & $(0.11-1.39)$ \\
\hline & $P$ for trend & & 0.08 & & 0.11 \\
\hline \multirow[t]{4}{*}{ Total LZ † } & $<0.25$ & 1.0 & & 1.0 & \\
\hline & $0.25-0.56$ & 0.48 & $(0.23-1.01)$ & 0.45 & $(0.20-1.01)$ \\
\hline & $\geq 0.56$ & 0.21 & $(0.05-0.82)$ & 0.21 & $(0.05-0.79)$ \\
\hline & $P$ for trend & & 0.009 & & 0.01 \\
\hline \multirow[t]{4}{*}{ Beta-carotene } & $<0.27$ & 1.0 & & 1.0 & \\
\hline & $0.27-0.97$ & 0.61 & $(0.27-1.39)$ & 0.62 & $(0.28-1.35)$ \\
\hline & $\geq 0.97$ & 0.55 & $(0.18-1.71)$ & 0.56 & $(0.18-1.75)$ \\
\hline & $P$ for trend & & 0.29 & & 0.29 \\
\hline \multirow[t]{4}{*}{ Alpha-carotene } & $<0.04$ & 1.0 & & 1.0 & \\
\hline & $0.04-0.20$ & 0.94 & $(0.44-1.99)$ & 0.93 & $(0.44-1.97)$ \\
\hline & $\geq 0.20$ & 0.33 & $(0.09-1.15)$ & 0.30 & $(0.08-1.09)$ \\
\hline & $P$ for trend & & 0.06 & & 0.05 \\
\hline \multicolumn{2}{|c|}{ Beta-cryptoxanthin $<0.13$} & 1.0 & & 1.0 & \\
\hline & $0.13-0.47$ & 1.20 & $(0.47-3.05)$ & 1.18 & $(0.48-2.92)$ \\
\hline & $\geq 0.47$ & 1.08 & $(0.35-3.29)$ & 1.16 & $(0.39-3.44)$ \\
\hline & $P$ for trend & & 0.87 & & 0.77 \\
\hline \multirow[t]{4}{*}{ Lycopene } & $<0.22$ & & & & \\
\hline & $0.22-0.71$ & 0.90 & $(0.40-2.01)$ & 0.92 & $(0.40-2.10)$ \\
\hline & $\geq 0.71$ & 0.34 & $(0.10-1.20)$ & 0.38 & $(0.10-1.39)$ \\
\hline & $\mathrm{P}$ for trend & & 0.14 & & 0.21 \\
\hline
\end{tabular}

Estimations were done using General Estimating Equation (GEE) logistic models, taking into account the data of both eyes and their correlation.

* multivariate adjustment for age, gender, smoking, lipid-standardized alpha-tocopherol, HDLcholesterol, BMI.

†Total LZ = lutein + zeaxanthin + dehydro-lutein 
Table 3. Age- and gender adjusted associations of plasma lutein and zeaxanthin with cataract in the POLA Study (odds-ratio (95 \% confidence interval).

\begin{tabular}{|c|c|c|c|c|c|c|c|c|c|c|c|c|c|}
\hline \multicolumn{2}{|c|}{$\begin{array}{l}\text { Plasma carotenoids } \\
(\mu \mathrm{mol} / \mathrm{l})\end{array}$} & \multicolumn{2}{|c|}{$\begin{array}{l}\text { Nuclear only } \\
\text { (86 eyes) }\end{array}$} & \multicolumn{2}{|c|}{$\begin{array}{l}\text { Cortical only } \\
\text { (47 eyes) }\end{array}$} & \multicolumn{2}{|c|}{$\begin{array}{l}\text { PSC only } \\
\text { (98 eyes) }\end{array}$} & \multicolumn{2}{|c|}{$\begin{array}{l}\text { Mixed } \\
\text { (93 eyes) }\end{array}$} & \multicolumn{2}{|c|}{$\begin{array}{l}\text { Cataract surgery } \\
\text { (94 eyes) }\end{array}$} & \multicolumn{2}{|c|}{$\begin{array}{l}\text { Any Cataract } \\
\text { ( } 418 \text { eyes) }\end{array}$} \\
\hline \multirow[t]{4}{*}{ Lutein } & $<0.17$ & 1.0 & & 1.0 & & 1.0 & & 1.0 & & 1.0 & & 1.0 & \\
\hline & $0.17-0.41$ & 0.79 & $(0.41-1.53)$ & 0.80 & $(0.33-1.94)$ & 1.17 & $(0.55-2.48)$ & 0.87 & $(0.40-1.87)$ & 0.83 & $(0.39-1.76)$ & 0.85 & $(0.56-1.30)$ \\
\hline & $\geq 0.41$ & 0.60 & $(0.24-1.47)$ & 0.75 & $(0.23-2.47)$ & 1.26 & $(0.52-3.07)$ & 0.75 & $(0.27-2.10)$ & 1.07 & $(0.41-2.77)$ & 0.82 & $(0.48-1.41)$ \\
\hline & $P$ for trend & & 0.26 & & 0.63 & & 0.60 & & 0.59 & & 0.93 & & 0.48 \\
\hline \multirow[t]{4}{*}{ Zeaxanthin } & $<0.04$ & 1.0 & & 1.0 & & 1.0 & & 1.0 & & 1.0 & & 1.0 & \\
\hline & $0.04-0.09$ & 0.47 & $(0.25-0.88)$ & 0.60 & $(0.24-1.48)$ & 1.22 & $(0.60-2.48)$ & 1.00 & $(0.44-2.26)$ & 0.69 & $(0.33-1.43)$ & 0.70 & $(0.46-1.05)$ \\
\hline & $\geq 0.09$ & 0.25 & $(0.08-0.71)$ & 1.09 & $(0.37-3.26)$ & 0.84 & $(0.34-2.07)$ & 0.66 & $(0.23-1.91)$ & 0.75 & $(0.30-1.89)$ & 0.57 & $(0.34-0.95)$ \\
\hline & $\mathrm{P}$ for trend & & 0.004 & & 0.83 & & 0.68 & & 0.49 & & 0.52 & & 0.03 \\
\hline \multirow[t]{4}{*}{ Dehydro-lut } & ein $<0.03$ & 1.0 & & 1.0 & & 1.0 & & 1.0 & & 1.0 & & 1.0 & \\
\hline & $0.03-0.07$ & 0.81 & $(0.42-1.58)$ & 0.84 & $(0.33-2.13)$ & 1.05 & $(0.51-2.15)$ & 1.53 & $(0.69-3.42)$ & 0.98 & $(0.46-2.09)$ & 0.90 & $(0.59-1.37)$ \\
\hline & $\geq 0.07$ & 0.34 & $(0.11-1.04)$ & 0.89 & $(0.28-2.86)$ & 0.97 & $(0.41-2.30)$ & 0.74 & $(0.24-2.27)$ & 0.86 & $(0.31-2.36)$ & 0.69 & $(0.40-1.20)$ \\
\hline & $P$ for trend & & 0.05 & & 0.85 & & 0.94 & & 0.76 & & 0.78 & & 0.19 \\
\hline \multirow[t]{4}{*}{ Total LZ * } & $<0.25$ & 1.0 & & 1.0 & & 1.0 & & 1.0 & & 1.0 & & 1.0 & \\
\hline & $0.25-0.56$ & 0.66 & $(0.34-1.29)$ & 0.78 & $(0.32-1.90)$ & 1.10 & $(0.53-2.28)$ & 0.66 & $(0.32-1.37)$ & 0.66 & $(0.32-1.38)$ & 0.70 & $(0.46-1.07)$ \\
\hline & $\geq 0.56$ & 0.53 & $(0.21-1.36)$ & 0.76 & $(0.23-2.52)$ & 1.08 & $(0.45-2.62)$ & 0.45 & $(0.16-1.30)$ & 0.85 & $(0.33-2.18)$ & 0.65 & $(0.38-1.11)$ \\
\hline & $\mathrm{P}$ for trend & & 0.17 & & 0.65 & & 0.87 & & 0.13 & & 0.67 & & 0.11 \\
\hline
\end{tabular}

Estimations were done using General Estimating Equation (GEE) logistic models, taking into account the data of both eyes and their correlation.

* Total LZ = lutein + zeaxanthin + dehydro-lutein 
Table 4. Age- and gender adjusted associations of other plasma carotenoids with cataract in the POLA Study (odds-ratio (95\% confidence interval).

\begin{tabular}{|c|c|c|c|c|c|c|c|c|c|c|c|c|c|}
\hline \multicolumn{2}{|c|}{$\begin{array}{l}\text { Plasma carotenoids } \\
(\mu \mathrm{mol} / \mathrm{l})\end{array}$} & \multicolumn{2}{|c|}{$\begin{array}{l}\text { Nuclear only } \\
\text { (86 eyes) }\end{array}$} & \multicolumn{2}{|c|}{$\begin{array}{l}\text { Cortical only } \\
\text { (47 eyes) }\end{array}$} & \multicolumn{2}{|c|}{$\begin{array}{l}\text { PSC only } \\
\text { (98 eyes) }\end{array}$} & \multicolumn{2}{|c|}{$\begin{array}{l}\text { Mixed } \\
\text { (93 eyes) }\end{array}$} & \multicolumn{2}{|c|}{$\begin{array}{l}\text { Cataract surgery } \\
\text { (94 eyes) }\end{array}$} & \multicolumn{2}{|c|}{$\begin{array}{l}\text { Any Cataract } \\
\text { (418 eyes) }\end{array}$} \\
\hline \multirow[t]{4}{*}{ Beta-carotene } & $<0.27$ & 1.0 & & 1.0 & & 1.0 & & 1.0 & & 1.0 & & 1.0 & \\
\hline & $0.27-0.97$ & 0.63 & $(0.33-1.23)$ & 1.67 & $(0.55-5.10)$ & 1.01 & $(0.51-2.04)$ & 0.77 & $(0.36-1.63)$ & 0.83 & $(0.39-1.75)$ & 0.89 & $(0.58-1.35)$ \\
\hline & $\geq 0.97$ & 0.42 & $(0.16-1.12)$ & 1.10 & $(0.28-4.26)$ & 0.51 & $(0.19-1.36)$ & 0.50 & $(0.18-1.38)$ & 0.81 & $(0.32-2.08)$ & 0.69 & $(0.40-1.19)$ \\
\hline & $P$ for trend & & 0.07 & & 0.93 & & 0.16 & & 0.17 & & 0.68 & & 0.17 \\
\hline \multicolumn{2}{|c|}{ Alpha-carotene $<0.04$} & 1.0 & & 1.0 & & 1.0 & & 1.0 & & 1.0 & & 1.0 & \\
\hline & $0.04-0.20$ & 1.30 & $(0.60-2.80)$ & 0.99 & $(0.39-2.52)$ & 0.88 & $(0.45-1.74)$ & 0.78 & $(0.35-1.76)$ & 0.69 & $(0.34-1.41)$ & 0.88 & $(0.58-1.33)$ \\
\hline & $\geq 0.20$ & 0.76 & $(0.29-2.03)$ & 0.97 & $(0.32-2.91)$ & 0.72 & $(0.30-1.73)$ & 0.54 & $(0.19-1.53)$ & 0.49 & $(0.19-1.32)$ & 0.71 & $(0.42-1.22)$ \\
\hline & $P$ for trend & & 0.52 & & 0.96 & & 0.46 & & 0.24 & & 0.15 & & 0.21 \\
\hline \multirow[t]{4}{*}{ Beta-cryptox. } & $<0.13$ & 1.0 & & 1.0 & & 1.0 & & 1.0 & & 1.0 & & 1.0 & \\
\hline & $0.13-0.47$ & 0.68 & $(0.35-1.31)$ & 1.18 & $(0.46-3.04)$ & 1.04 & $(0.53-2.04)$ & 0.96 & $(0.47-1.98)$ & 0.58 & $(0.28-1.18)$ & 0.84 & $(0.55-1.26)$ \\
\hline & $\geq 0.47$ & 0.70 & $(0.29-1.68)$ & 1.49 & $(0.48-4.68)$ & 0.42 & $(0.15-1.18)$ & 0.59 & $(0.22-1.60)$ & 0.82 & $(0.34-1.98)$ & 0.71 & $(0.42-1.20)$ \\
\hline & $P$ for trend & & 0.44 & & 0.49 & & 0.09 & & 0.30 & & 0.70 & & 0.20 \\
\hline \multirow[t]{4}{*}{ Lycopene } & $<0.22$ & 1.0 & & 1.0 & & 1.0 & & 1.0 & & 1.0 & & 1.0 & \\
\hline & $0.22-0.71$ & 0.92 & $(0.46-1.82)$ & 0.92 & $(0.36-2.33)$ & 1.04 & $(0.51-2.12)$ & 1.76 & $(0.79-3.93)$ & 1.23 & $(0.57-2.64)$ & 1.02 & $(0.67-1.56)$ \\
\hline & $\geq 0.71$ & 1.01 & $(0.41-2.51)$ & 0.92 & $(0.27-3.13)$ & 1.19 & $(0.49-2.88)$ & 2.11 & $(0.71-6.27)$ & 1.01 & $(0.36-2.85)$ & 1.17 & $(0.68-2.01)$ \\
\hline & $P$ for trend & & 0.99 & & 0.89 & & 0.70 & & 0.16 & & 0.92 & & 0.58 \\
\hline
\end{tabular}

Estimations were done using General Estimating Equation (GEE) logistic models, taking into account the data of both eyes and their correlation. 